Archives of Agriculture and Environmental Science

\title{
Effects of oxytetracycline residues in Thai Koi (Anabas testudineus Bloch) collected from Sylhet, Bangladesh
}

\author{
A.K. Apurbo Barman ${ }^{1}$, Md. Motaher Hossain ${ }^{1}$, Md. Golam Rasul ${ }^{2 *}$ iD, Bhaskar Chandra \\ Majumdar $^{2}$ and Md. Matiur Rahim ${ }^{3}$ \\ ${ }^{1}$ Department of Fisheries Technology and Quality Control, Sylhet Agricultural University, Sylhet, BANGLADESH \\ ${ }^{2}$ Department of Fisheries Technology, Bangabandhu Sheikh Mujibur Rahman Agricultural University, Gazipur-1706, BANGLADESH \\ ${ }^{3}$ Institute of Food science and Technology, Bangladesh Council of Scientific and Industrial Research, Dhaka, BANGLADESH \\ "Corresponding author's E-mail: rasul.gsau@gmail.com
}

\section{ARTICLE HISTORY}

Received: 23 March 2018

Revised received: 16 April 2018

Accepted: 04 May 2018

\section{Keywords}

Anabas testudineus

High Performance Liquid

Chromatography

Oxytetracycline

Recommended level

\section{ABSTRACT}

The present study was conducted to determine the levels of oxytetracycline residues in Thai Koi (Anabas testudineus Bloch) collected from some local fish markets of Sylhet Sadar Upazilla, Bangladesh during March to August, 2016. For the purpose of the study, 24 fresh Thai Koi fish samples were randomly collected from four (4) local markets of Sylhet Sadar Upazilla. Concentration of oxytetracycline residues in collected fish samples were determined by High Performance Liquid Chromatography (HPLC) at the Food Toxicology Laboratory of Institute of Food Science and Technology, Bangladesh Council of Scientific and Industrial Research, Dhaka. The results showed that 9 (37.50\%) samples with detectable amount of oxytetracycline residues (mean $=42.30 \pm 3.00 \mathrm{ppb}$ ) were found in Thai Koi. Oxytetracycline residues level below detection limit was also reported in 15 (62.50\%) samples of Thai Koi during this study. The detected residues of oxytetracycline in this fish sample did not exceed the maximum residue limit (MRL) 100 ppb recommended by the European Commission. Though residue level of oxytetracycline is lower than the MRL but long term exposure could be hazardous for human health. For that reason, control of antibiotic usage in aquaculture, regular residue monitoring, legislations and regulations for the use of antimicrobials in aquaculture and food safety education are utmost things in this regard.

(C)2018 Agriculture and Environmental Science Academy

Citation of this article: Barman, A.K.A., Hossain, M.M., Rasul, M.G., Majumdar, B.C. and Rahim, M.M. (2018). Effects of oxytetracycline residues in Thai Koi (Anabas testudineus Bloch) collected from Sylhet, Bangladesh. Archives of Agriculture and Environmental Science, 3(2): 174-179, https://dx.doi.org/10.26832/24566632.2018.0302011

\section{INTRODUCTION}

Bangladesh is uniquely rich in productive water resources and blessed with diversified fisheries resources (Kibria and Ahmed, 2005) which are composed of 260 freshwater native species, 12 species of exotic fishes, 24 species of freshwater prawn, 475 marine fish species and 36 species of marine shrimp (Haque, 2005). In Bangladesh, about 63\% animal protein of our meal comes from fisheries resources (Ahmed, 2005). That's why fish and fisheries are the essential part of Bangladeshi people from the time immemorial and play a dynamic role in the meeting up nutritional demand, generating employment, earning foreign currency and other aspects of the economy (Alam, 2002). On the other hand due to favorable climatic condition the water bodies are highly productive and aquaculture is an important commercially viable activity and also plays a major role in country's total production from fisheries sector (DoF, 2003). Thai koi (Anabas testudineus) is one of the common exotic fish species in Bangladesh. It is considered as an economic and important fish because of its high market demand, potentialities for intensive culture of species, having shorter life cycle, faster growth rate and high nutritious food value and delicious taste (Kohinoor et al., 2010).

Different infectious and non-infectious diseases constitute major constraints to aquaculture production (Bagumire et al., 2010). In Bangladesh, disease outbreaks have been recognized 
as one of the main constraint to the development of the aquaculture sector in Bangladesh (Karim et al., 2012). Most of the freshwater fish species are affected by different types of disease, causing significant monetary loses (Hasan et al., 2013). In modern culture system different types of therapeutic agents and aqua chemicals are used to treat affected animals (Rico et al., 2013). Where, oxytetracycline (OTC), a group of tetracyclines is the primary anti-bacterial, effective against a wide range of Gram-positive and Gram-negative bacteria, including the Gram-negative Vibrio spp. used in most aquaculture production (Erdogdu, 2012). Oxytetracycline $\left(\mathrm{C}_{22} \mathrm{H}_{24} \mathrm{~N}_{2} \mathrm{O}_{9}\right)$ has been used in aquaculture as a therapeutic and prophylactic agent because of its broad-spectrum activity (Figure 1). About 70-80\% of drugs used in aquaculture end up in the environment which can be transferred to human beings through food of contact with the fish or water (Serrano, 2005). Antibiotic residues transferred to humans through food can also alter the intestinal ecology thereby favoring the emergence of resistant micro flora (Perrin-Guyomard et al., 2001). So, there is a global concern about the consumption of aquatic food containing low levels of antibiotics.

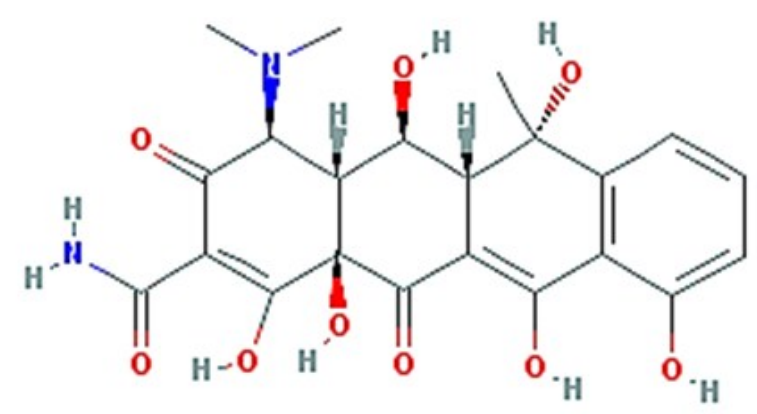

Figure 1. Structure of Oxytetracycline

However, in Bangladesh indiscriminate administrations of oxytetracycline in fish culture have been reported by several authors but quantitative risks assessment of antimicrobial residues in fishes is limited. A few numbers of studies have been reported on the monitoring of oxytetracyclines residues in fishes comes from the aquaculture systems. The present study was designed to determine the occurrence of oxytetracycline residues in Thai koi fish which are marketed in local fish markets of Sylhet Sadar region of Bangladesh.

\section{MATERIALS AND METHODS}

\section{Study area}

This study was carried out in Sylhet Sadar Upazilla, the southeastern part of Bangladesh. The Experimental fish were collected from four (4) selected fish markets of Sylhet Sadar Upazilla. The selected fish markets were Kazir Bazar, Baluchar Noya Bazar, Mejor Tilah Bazar and Tuker Bazar under the study area.

\section{Collection of fish sample}

For analysis purposes 24 samples of Thai Koi (Anabas testudineus) were collected between the periods March to August, 2016. At first fish samples were collected individually from the selected fish markets in separate marked polythene bags and were kept in an ice box. After collection of fish samples, they were transported to Microbiology Laboratory of Department of Fisheries Technology and Quality Control, Sylhet Agricultural University, Sylhet and kept in a deep refrigerator. For analyzing purpose then the samples were transported to Food Toxicology Laboratory of Bangladesh Council of Scientific and Industrial Research, Dhaka with icing condition and kept in a deep refrigerator at $-20^{\circ} \mathrm{C}$ prior to analysis.

HPLC analysis of oxytetracycline residue in Thai Koi muscle samples

Agilent (1100 series) solvent delivery system (Isocratic pump) connected Fluorescence detector with C18 (Phenomenex Gemini $5 \mu, 250$ '4.60 mm) column were used as HPLC device. Manual injector capable of injection volumes was up to 50 microliters. Laboratory grade Oxytetracycline hydrochloride (Sigma Aldrich), Methanol - HPLC grade (Merck), Magnesium Acetate (Extra Pure, BDH), Citric Acid - Monohydrate (Merck), Sodium Hydrogen phosphate - anhydrous (Merck), EDTA disodium dehydrate (Scharlu), Acetic acid (Riedel de Haein), Imidazole (Merck), n-Hexane (Merck) and HPLC grade water were used as necessary chemicals. Mcllvaine Buffer, Mcllvaine Solution (Mcllvaine Buffer/0.1 M EDTA), Extraction Solution, Imidazole Buffer (1M) and Mobile Phase (Buffer and Methanol ratio of 70:30 v/v) were also utilized as various solutions.

\section{Preparation of calibration curve}

Calibration curve (Figure 2) was prepared from injecting corresponding concentrations of oxytetracycline standard solution of $25,50,75,100,125$ and $150 \mathrm{ppb}$.

The linear fit curve obtained using-

$y=m x+b ;=0.0132368 x+0.04568$

Where, $y=$ peak area and $x=$ concentration of oxytetracycline (ppb) and the correlation coefficient $\left(r^{2}\right)=0.99687$. The detection limit for oxytetracycline was $23.62 \mathrm{ppb}$. The mean retention times (RT) of the oxytetracyclines were found between 4.031 to 4.25 minutes.

Preparation of muscle for analysis of antibiotic residue After adequate thawing of frozen fish, about 20 gm of muscle sample were collected from the dorso-lateral area of fish and minced using chopping board and knife. Then weighed $5.0 \mathrm{gm}$ minced muscle samples were taken into $50 \mathrm{~mL}$ polypropylene centrifuge tubes. Then $20 \mathrm{~mL}$ extraction solution was added to each sample and homogenized by using Ultra Turrax until samples were uniformly blended (15-30 seconds). After rinsing probe with $4 \mathrm{~mL}$ of extraction solution, rinses were added to centrifuge tube. Tubes were capped and shaken 10 minutes on a flatbed shaker at speed. Contents of tubes were centrifuged at a minimum $8000 \mathrm{rpm}$ for 20 minutes at approximately $15^{\circ} \mathrm{C}$. Supernatants were poured into a second centrifuge tube carefully not to transfer any tissue. Five (5) $\mathrm{mL} n$-Hexane was added to solution and briefly shaked. Upper layer was removed. A 
single Whatman \#1 filter paper was placed into a $5.5 \mathrm{~cm}$ Bucher filtering funnel and attached to a $250 \mathrm{~mL}$ sidearm flask with vacuum condition. Centrifuge tubes were rinsed with $4 \mathrm{~mL}$ Extraction solution and filtered into a flask. An SPE (Solid Phase Extraction) cartridge was attached to an SPE vacuum manifold. The cartridge was conditioned with $10 \mathrm{~mL}$ methanol followed by $15-20 \mathrm{~mL}$ distilled water at approximately $1.5-2.5 \mathrm{~mL} /$ minute with vacuum as necessary. The elute were discarded. A $75 \mathrm{~mL}$ reservoir was connected to the cartridge. The filtered sample extracts were added to the SPE reservoir. The flask was rinsed with approximately $4 \mathrm{~mL}$ buffer solution and was added to the rinses to the reservoir. Extract was drained through the column by gravity. The sidearm flask was rinsed with $20 \mathrm{~mL}$ distilled water and added to reservoir. After draining under - $10 \mathrm{~mm} \mathrm{Hg}$ vacuum, cartridges were allowed to go dry after the water rinse is completed, and continue to draw air through the cartridge for at least 2 minutes. Then Elute was discarded. A $15 \mathrm{~mL}$ graduated centrifuge tube was placed in the vacuum apparatus to serve as a collection vessel and elute oxytetracycline from the cartridge with $6 \mathrm{~mL}$ elution solution. Vacuum condition was applied to initiate flow continue elution. Once flow stops, vacuum applied to remove residual solvent from the cartridge. Tubes were removed from vacuum manifold and vortex was done. The tube containing elute were placed in the sample concentrator at the temperature at $40-50^{\circ} \mathrm{C}$ to reduce volume of the elute to 0.5 $0.25 \mathrm{~mL}$ under a stream of dry nitrogen. Final volume was adjusted to1 $\mathrm{mL}$ with methanol + water (1:1) and briefly vortexing. Then approximately $1.0 \mathrm{~mL}$ extract were drawn into a $3 \mathrm{~mL}$ syringe and was filtered through a syringe into an HPLC vial (1.5 $\mathrm{mL})$. The remaining extract was store at $-20^{\circ} \mathrm{C}$.

\section{HPLC condition for analysis of oxytetracycline residues}

The concentrate extract were subjected to analysis by Agilent 1100 series HPLC system. For analyzing purpose $20 \mathrm{~mL}$ extract volume were injected to HPLC system. Flow rate was maintained $1 \mathrm{~mL} / \mathrm{min}$ and column temperature was $30^{\circ} \mathrm{C}$. Excitation wavelength and emission wavelength were $380 \mathrm{~nm}$ and $520 \mathrm{~nm}$, respectively.

\section{Recovery evaluation}

The precision of the method was determined as recoveries of oxytetracycline spiked blank samples. For this two replicate oxytetracycline free fish samples were spiked with $150 \mathrm{ppb}$ oxytetracycline standard just before test.

\section{Statistical analysis}

For preliminary processing of raw data obtained from this study was analysis by using the Microsoft Excel, SPSS software etc.

\section{RESULTS AND DISCUSSION}

\section{Oxytetracycline residues obtained from Thai Koi samples}

Results are presented in tabular forms which are obtained from the chromatogram of the analyzed samples and oxytetracycline residues analysis of Thai Koi is given in Table 1. The mean of the detected oxytetracycline residues were calculated as Mean \pm SEM (Standard Error Mean). In total 24 fish samples obtained from the local fish markets, detectable amount of oxytetracycline residues were detected in 9 (37.50\%) Thai Koi samples (Figure 3). The range of detected oxytetracycline concentrations of positive samples (Table 1) were between 29.61 - 55.98 $\mathrm{ppb}$ (mean $=42.3 \pm 3.00 \mathrm{ppb}$ ).

Most of the positive samples contained oxytetracycline at the range of $29.61-55.98 \mathrm{ppb}$. According to the results of this study, 9 (37.50\%) samples of Thai Koi were contaminated with oxytetracycline residues. In this experiment no samples exceed the maximum residue limits (MRL) of oxytetracycline (100 ppb) set by European Commission (2010). The obtained result agrees well with the findings of Fortt et al. (2007), where they analyzed the presence of oxytetracycline in 13 salmon fish samples caught in farms. Eighty-seven (87) ppb oxytetracycline residues was detected in one fish and oxytetracycline levels of fish caught in the sea were below the levels laid down by Chilean fisheries authorities (tetracyclines $100 \mathrm{ppb}$ ).

Shim et al. (2010) also reported up to $60 \mathrm{ppb}$ of oxytetracycline residues in farmed fish that were caught in their natural habitat. They reported that detected levels of oxytetracycline residues were below the maximum residue limit (MRL) laid down in Korean Food Legislation. Lower amount of oxytetracycline than maximum residue limits set by Codex Alimentarius were also found in $6 \%$ (3) of the samples before frying and $24 \%$ (12) of the samples after frying in Rainbow trout (Oncorhynchus mykiss) meat in Shahre-kord, Iran reported by Sharafati-Chaleshtori et al. (2013), where the study was conducted to evaluate the oxytetracycline residues in 50 Rainbow trout meat after collection from the markets.

A study was conducted by Barani and Fallah (2015), carried out to determine the occurrence of tetracyclines residues in 138 rainbow trout muscle samples obtained from Iranian trout farms. Where they reported at measurable levels $63.1 \%$ of the samples were contained with the residues of tetracyclines in which maximum sample contained residues at a range 1.43 $91.130 \mathrm{ppb}$ and only one sample (101.40 ppb) exceeds the maximum residue limit of oxytetracycline set by the European Commission.

Turk and Oguz (2016) demonstrated a research to observe the residual effects of tetracyclines (oxytetracycline, tetracycline, chlortetracycline, and doxycycline) in 70 fish samples from 70 various fish farms in Mugla province of Turkey. No tetracycline antibiotic residues were found, cross the detection limit. The result is also line with some findings of Shim et al. (2010), where they also did not found any oxytetracycline residues in some examined fish. Baydan et al. (2015), where they did not found any samples of fish (Oblada melanura, Mullus barbatus) collect from the natural habitat exceeding the detection limit according to their used method. A recent study of Barani and Fallah (2015) reported tetracyclines residues in $36.9 \%$ trout samples were less than detection limit of competitive enzyme-linked immunosorbent assay method. Mahmoudi et al. (2014) also reported $8.44 \pm 6.03 \mathrm{ppb}$ tetracyclines residues in Oncorhynchus 
mykis and the confined tetracyclines residues were lower than the than detection limit of present study.

In addition, irresponsible uses of oxytetracycline in aquaculture sometimes lead negative impact when deposited in fish muscle as residues. Many authors also reported heavy deposition of oxytetracycline in fish higher than the maximum residue limit (100 ppb) set by European Commission (2010). Erdogdu (2012) reported exceeded levels of oxytetracycline than maximum re-sidue limit (MRL; $100 \mathrm{ppb}$ ) in five samples during a study within the scope of Residue Monitoring Plan for 2006-2012 to investigate the presence of tetracycline residues. The presence of tetracycline residues were analyzed in 613 samples of aquaculture products at Bornova Veterinary Control and Research Institute Toxicology Laboratory, Turkey. Similar results also found by Segmenoglu (2014) where they found oxytetracycline residues in three fish samples were exceeded maximum residue limit lay down in the codex (100 ppb). In a recent survey conducted in Nigeria, Olatoye and Basiru (2013) reported oxytetracycline residues in the muscle samples of 160 cat fish collected from fish farms and restaurants. They reported $30 \%$ of the fillet samples contained oxytetracycline, ranging between 22.5 and $553.2 \mathrm{ppb}$, and $18.8 \%$ of the samples exceeded the limit of 200 ppb established by the Codex Alimentarius Commission.

Result of the present study revealed that oxytetracycline is widely used in fish health management and disease treatment by the farmers and some farmers marketed their fish without following the prescribed withdrawal period of this antibiotic. In this study, numbers of samples (9) with detectable amount of oxytetracycline were found in Thai Koi. This result agree with the finding of Ali et al. (2016), where they reported that the proportion of farmers using antibiotics within the koi farm group (15\% of farms). They also reported Koi and Pangas farmers used the most varied of antibiotics and oxytetracycline is the most commonly used antibiotic compounds followed by others. As a result oxytetracycline could come into contact with humans by means of the food chain (Kan and Meijer, 2007). On the other hand antibiotic residues around fish farms also resulted in emergence of antibiotic-resistant bacteria in aquaculture environments, increase in antibiotic resistance in fish pathogens as well as in the transfer of these resistance determinants to human pathogens (Victoria and Samanidou, 2007; Mastovska, 2011). Since residue level of antibiotic in food is a global concern in terms of food safety issue. Though detected levels of oxytetracycline in analyzed samples did not exceed the maximum residue limit (100 ppb) and this level are safe for human consumption. But their co-occurrence could be hazardous for public health in case of higher concentration with long term exposure. As fish farming is one of the popular business in Bangladesh different level of people are involve with it. A wide range of people who are directly involved with aquaculture are from different educational background. Most of them have no idea about the antibiotic usage and its withdrawal period when they apply for treatment in the culture pond. This practice can influence the presence of the antibiotic residue in fish.

Table 1. Occurrences of oxytetracycline residues in Thai Koi (Anabas testudineus).

\begin{tabular}{|c|c|c|c|c|c|}
\hline \multirow{2}{*}{ Samples ( $\mathrm{n})$} & \multicolumn{2}{|c|}{ Concentration of Oxytetracycline residue (ppb) } & \multicolumn{2}{|c|}{ Distribution of Samples, n (\%) } & \multirow{2}{*}{ Exceed $\mathrm{MRL}^{3} \mathrm{n}(\%)$} \\
\hline & Mean $\pm \mathrm{SEM}^{1}$ & Range & $\begin{array}{l}\text { Less than } \\
\text { LOD }^{2}\end{array}$ & $\begin{array}{l}\text { Positive samples } \\
\text { (LOD -100 ppb) }\end{array}$ & \\
\hline 24 & $42.3 \pm 3.00$ & $29.61-55.98$ & $15(62.50)$ & $9(37.50)$ & $0(0.00)$ \\
\hline
\end{tabular}

${ }^{1} \mathrm{SEM}=$ Standard Error Mean; ${ }^{2} \mathrm{LOD}=$ Limit of detection $=23.62 \mathrm{ppb} ;{ }^{3} \mathrm{MRL}=$ Maximum Residue Limits $=100 \mathrm{ppb}$

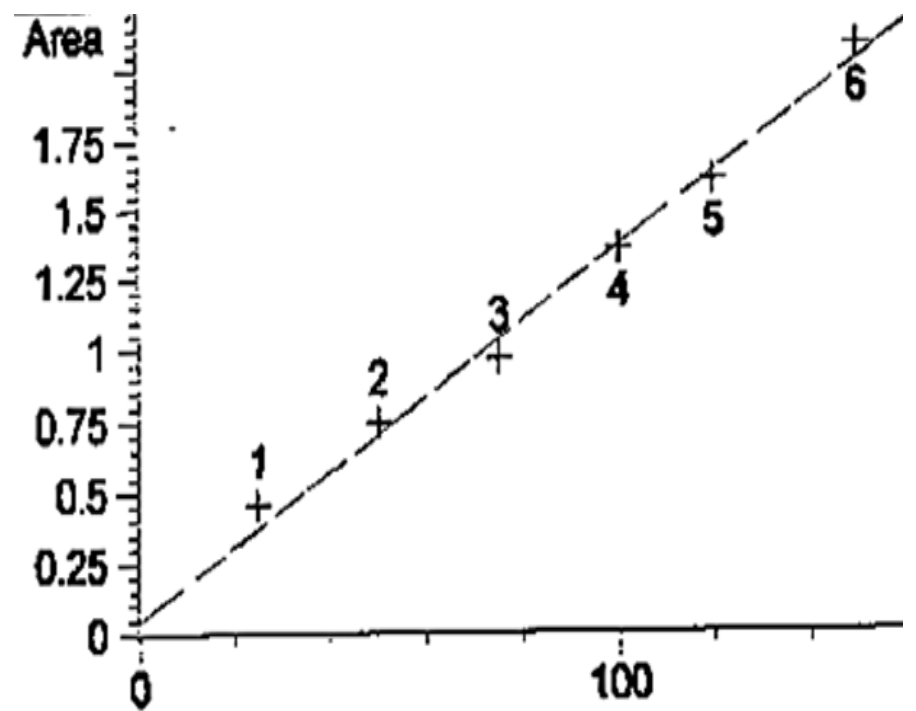

Amount [ppb]

Figure 2. Calibration curve.

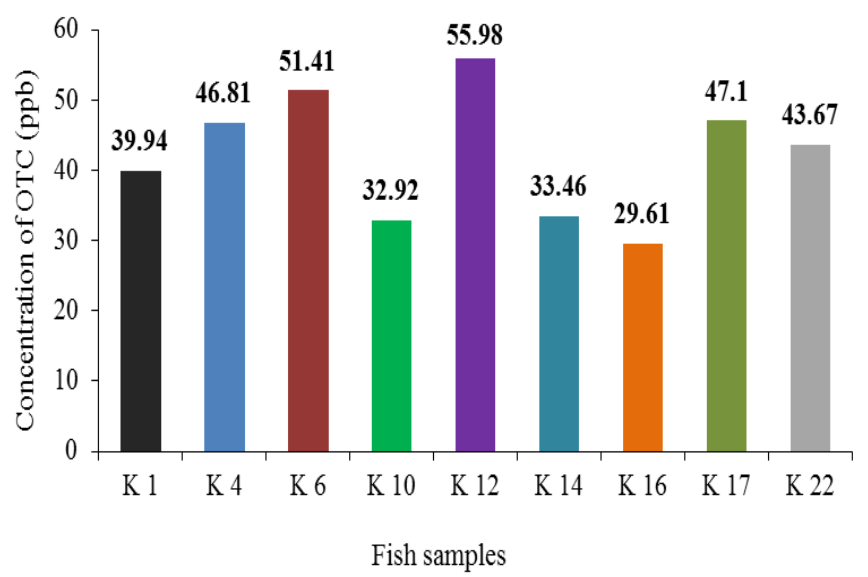

Figure 3. Detected oxytetracycline residues in Thai Koi, where, $K 1=$ Thai Koi Sample 1 (Kazir Bazar), K 4 = Thai Koi Sample 4 (Tuker Bazar), $K 6=$ Thai Koi Sample 6 (Baluchar Noya Bazar), K 10 = Thai Koi Sample 10 (Baluchar Noya Bazar), $K 12$ = Thai Koi Sample 12 (Tuker Bazar), $K 14=$ Thai Koi Sample 14 (Baluchar Noya Bazar), K 16 = Thai Koi Sample 16 (Tuker Bazar), $K 17$ = Thai Koi Sample 17 (Kazir Bazar) and K 22 = Thai Koi Sample 22 (Baluchar Noya Bazar). 
Conclusion

Results and findings of the present study shown that small portion of Thai Koi (Anabas testudineus) available in local fish markets of Sylhet Sadar Upazilla contaminated with oxytetracycline residues. About nine numbers of positive samples with detectable level of oxytetracycline residues were found during the study period. This residue occurrence indicates abuse of antibiotics in commercial fish production in this area without following specific rule and also indicates lack of farmer's awareness about antibiotic residue at the root level. Though, oxytetracycline residues found in the positive samples did not exceed the maximum residue limit recommended by the European Commission but it is an important indicator of antibiotic contamination in fish. Fish is considered as a major source of protein in Bangladesh and in these consequences some remedy measures should be taken to ensure better public health. That's why, arising of public awareness about antibiotic use and its withdrawal period, antibiotic residue monitoring of cultured fish species by governmental authority like Department of Fisheries (DoF), Fish Inspection and Quality Control (FIQC) and monitoring of antibiotic resistance bacteria from fish and farming environment are needed.

Open Access: This is open access article distributed under the terms of the Creative Commons Attribution License, which permits unrestricted use, distribution, and reproduction in any medium, provided the original author(s) and the source are credited.

\section{REFERENCES}

Ahmed, M.N.U. (2005). Fisheries sector in the economy of Bangladesh and its potential development (Published in Bengali) In: Souvenir of National Fish Fortnight (Matsya Pokkhya) 2005. Department of Fisheries, Dhaka, Bangladesh, pp. 11-15.

Alam, M.F. (2002). Socio-economic aspects of carp production and consumption in Bangladesh. Pp. 83-93. In: Penman, D.J., M.G. Hussain, B.J. McAndrew and M.A Mazid (eds.), Proceedings of a workshop on Genetic Management and Improvement Strategies for Exotic Carps in Asia. Dhaka, Bangladesh. Bangladesh Fisheries Research Institute, Mymensingh, Bangladesh, pp. 83.

Ali, H., Rico, A., Murshed-e-Jahan, K. and Belton, B. (2016). An assessment of chemical and biological product use in aquaculture in Bangladesh. Aquaculture, 454: 199-209, https:// dx.doi.org/10.1016/j.aquaculture.2015.12.025

Bagumire, A., Todd, E.C., Nasinyama, G.W. and Muyanja, C. (2010). Food safety-related control measures in emerging aquaculture enterprises in Sub-Saharan Africa: Compliance of Ugandas operations against international market requirements. African Journal of Food Science, 4(7): 444-457, http://www.academicjournals.org/journal/AJFS/article-full -text-pdf/F64F71725113

Barani, A. and Fallah, A.A. (2015). Occurrence of tetracyclines, sulfo-namides, fluoroquinolones and florfenicol in farmed rain-bow trout in Iran. Food and Agricultural Immunology, 26(3): 420-429, https://dx. doi.org /10.1080/09540105. 2014.950199

Baydan, E., Kaya, S., Çagirgan, H., Yildirim, E., Altintas, L., Yurdakok, B., Ekici, H., Aydin, F.G. and Kucukosmanoglu, A.G. (2015). Investi-gation of some veterinary drug residues in sea water, se-diment, and wild fishes captured around fish farms in the Aegean sea: Oxytetracyline, ivermectin and emamectin. Ankara Üniversitesi Veteriner Fakültesi Dergisi, 62(3): 171-176, http://dergiler. ankara.edu.tr/dergiler/11/1983/20722.pdf

DoF, Department of Fisheries. (2003). Sharonika, Matshya Pakha 2003 (in Bengali). Department of Fisheries, Ministry of Fisheries and Livestock, Government of the People's Republic of Bangladesh, pp. 13.

Erdogdu, A.T. (2012). Using antibiotics in aquatic living beings. Rational use of antibiotics and antimicrobial resistance symposium, Ankara, Turkey, pp. 87-95.

European Commission. (2010). Commission Regulation (EU) No. $37 / 2010$ of 22 December 2009 on pharmacologically active substances and their classification regarding maximum residue limits in foodstuffs of animal origin. Official Journal of the European Union, L15, pp. 1-72.

Fortt, Z.A., Cabello, C.F. and Buschmann, R.A. (2007). Residues of tetracycline and quinolones in wild fish living around a salmon aquaculture center in Chile. Revista chilena de infectologia: organo oficial de la Sociedad Chilena de Infectologia, 24(1): 14-18, https://dx.doi.org/ 10182007000100002

Haque, M.E. (2005). Brief History of Small and Extinct Fishes of Bangladesh (Published in Bengali). Department of Fisheries, Dhaka, Bangladesh.

Hasan, M.M., Faruk, M.A.R., Anka, I.Z. and Azad, M.A.K. (2013). Investigation on fish health and diseases in rural pond aquaculture in three districts of Bangladesh. Journal of Bangladesh Agricultural University, 11(2): 377-384.

Kan, C.A. and Meijer, G.L.A. (2007). The risk of contamination of food with toxic substances present in animal feed. Animal Feed Science and Technology, 133(1): 84-108, https:// dx.doi.org/10.1016/j.anifeedsci.2006.08.005

Karim, M., Sarwer, R.H., Brooks, A.C., Gregory, R., Jahan, K.M. and Belton, B. (2012). The incidence of suspected white spot syndrome virus in semi-intensive and extensive shrimp farms in Bangladesh: implications for management. Aquaculture Research, 43 (9): 1357-1371, https:// dx.doi.org/10.1111/j.1365-2109.2011.02939.x

Kibria, M.G. and Ahmed, K.K.U. (2005). Diversity of selective and non-selective fishing gear and their impact on inland fisheries in Bangladesh. Naga, World Fish Center Quarterly, 28(1-2): 43-48.

Kohinoor, A.H.M., Jahan, D.A., Khan, M.M. and Hossain, M.G. (2010). Breeding, seed production and culture technology of koi fish. Extension Manual No. 39. Bangladesh Fisheries Institute. Freshwater Station, Mymensingh. 16 p. 
Mahmoudi, R., Gajarbeygi, P., Norian, R. and Farhoodi, K. (2014). Chloramphenicol, sulfonamide and tetracycline residues in cultured rainbow trout meat (Oncorhynchus mykiss). Bulgarian Journal of Veterinary Medicine, 17(2): 147-152.

Mastovska, K. (2011). Multiresidue analysis of antibiotics in food of animal origin using liquid chromatography-mass spectrometry. In: Mass Spectrometry in Food Safety: Methods and Protocols, J. Zweigenbaum (ed.), Springer, New York, USA. 267-307 pp.

Olatoye, I.O. and Basiru, A. (2013). Antibiotic Usage and Oxytetracycline Residue in African Catfish (Clarias gariepinus in Ibadan, Nigeria). World Journal of Fish and Marine Sciences, 5(3): 302-309, https://pdfs. semanticscholar. org/38ec/8fef85e17fbe634f114b69f5509922d79e03.pdf

Perrin-Guyomard, A., Cottin, S., Corpet, D.E., Boisseau, J. and Poul, J.M. (2001). Evaluation of residual and therapeutic doses of tetracycline in the human-flora-associated (HFA) mice model. Regulatory Toxicology and Pharmacology, 34 (2): 125-136, https://dx.doi.org/10.1006/rtph.2001.1495

Rico, A., Phu, T., Satapornvanit, K., Min, J., Shahabuddin, A.M., Henriksson, P.J.G. and Van den Brink, P.J. (2013). Use of veterinary medicines, feed additives and probiotics in four major internationally traded aquaculture species farmed in Asia. Aquaculture, 412: 231-243, https:dx.doi.org/10.1016/ j.aquaculture.2013.07.028

Segmenoglu, M.S. (2014). Searching some antibiotics that are tetracycline group in fish muscle tissue. AVKAE Magazine, 4: 25-29.

Serrano, H.P. (2005). Responsible use of antimicrobials in aquaculture. FAO Fisheries Technical Paper, 469. 1- 97 pp.

Sharafati-Chaleshtori, R., Mardani, G., Rafieian-Kopaei, M., Sharafati- Chaleshtori, A. and Drees, F. (2013). Residues of Oxytetracycline in Cultured Rainbow Trout. Pakistan Journal of Biological Science, 16(21): 1419-1422, https:// scialert.net/abstract/?doi=pjbs.2013.1419.1422

Shim, K.B., Mok, J.S., Jo, M.R., Kim, P.H., Lee, T.S., Kim, J.H. and Cho. Y.J. (2010). Residues of Antibiotics in Wild and Cultured Fishes Collected from Coast of Korea. Korean Journal of Fisheries and Aquatic Sciences, 43(1): 12-17, https://dx.doi.org/0.5657/kfas.2010.43.1.012

Turk, E. and Oguz, H. (2016). Investigation of tetracycline residues in fish caught from surrounding fish farms in Mu? Iadistrict. Eurasian Journal of Veterinary Sciences, 32 (2): 74-79, http://eurasianjvetsci.org/pdf/pdf_EJVS_1112.pdf

Victoria, F. and Samanidou, N.E. (2007). Analytical strategies to determine antibiotic residues in fish. Journal of Separation Science, 30(16): 2549-2569, https://dx.doi.org/10.1002m jssc. 200700252 